\title{
SUPPORTING A PROFESSION IN TURMOIL
}

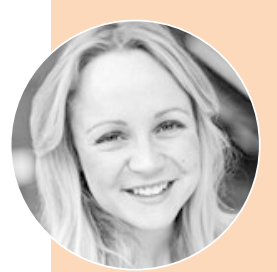

\section{Coronavirus update}

Coronarvirus has created a clinical and financial crisis for dental practices across the UK. Social distancing measures and extended decontamination times have resulted in huge reductions in the capacity of high street practices. To compound the problem, shrinking PPE stocks and rising costs have created a perfect storm, resulting in many practices facing closure.

Whilst the NHS benefited from the luxury of 'an open purse' from the Government to provide essential care to protect the public, dentistry has, once again, largely been left behind. With the future of the profession as we know it in jeopardy, we have relentlessly pressed Government for additional support.

We have stood alongside the profession, initially when dental practices closed at the start of the lockdown, then later when practices reopened under radically new operating procedures. We called on NHS England to include dentists in the PPE supply chain, which they have now promised. We've secured a financial safety net for NHS contractors and their associates in all four UK nations. We got nearly two hundred MPs to press the Chancellor to offer real support to self-employed dentists and private practice. To protect associates, we also launched an associate pay dispute resolution service to ensure that any issues are resolved in a fair and satisfactory way.

At the time of writing this article, bankers, religious staff and even journalists had 'key worker' status, so could access childcare if needed. Whilst dentists, frustratingly, were not included on the essential worker list. We have demanded that dentists and team members are given key worker status, so they can finally send their children to school and resume their rightful position as caretakers of the nation's oral health.

We have been working hard trying to get your stories out in the local and national media to explain why huge numbers of patients can't be seen. We also outlined what patients will experience when practice reopened, so their expectations were in line with our ability to treat them.

We will continue to do everything in our power to ease what is a tremendously difficult situation for UK dentists: lobbying Government, providing financial and emotional support, and delivering practical advice to support the profession in its 'new normal'.

We are a democratic trade union, set up by dentists for dentists. By being a member, your support allows us to continue this important work. Together we are stronger.

Stay up to date with the latest developments at www.bda.org/coronavirus.

\section{Supporting final year students}

With the end of dental school looming, we are here to help you prepare for the world of work with a tailored package of benefits:

- Getting Your First Job guide. This detailed guidebook is designed to help you with the next step in your dental career - securing your first job. Covers both the national and Scottish recruitment systems

- Interview skills lectures - delivered to your dental school

- Dental Foundation Training Intensive workshop - a one day workshop.

Student pricing for final year students ends on 30 November 2020. After this date pricing for new joiners will increase from $£ 2.50$ a month to $£ 418$ a year - the full dentist rate.

If you're already a member this pricing change doesn't affect you - your pricing won't change and you don't need to do anything. If you maintain continuous membership up to graduation, you'll also qualify for the $£ 250$ saving on membership fees after graduation.

With the extended closure of dental schools over lockdown, catching up with your studies may feel like a steep mountain to climb. Try not to put too much pressure on yourself. Like the rest of the UK economy, your dental education has gone through an unprecedented period of disruption. You have lots of support around you, both within your dental school and via the $\mathrm{BDA}$, so it is important to reach out if you feel you need extra help - clinically, financially or emotionally. We are here to help.

\section{Laura Assassa}

\section{Membership benefits summary}

Here's a quick recap of your student member benefits:

- Protecting your profession

- Negotiating on your behalf as your dental trade union

- Supporting your studies

- Online access to the $B D J$ and $B D J$ In Practice and copies posted to your door in years 3-5

- BDJ Student magazine - for tailored careers and clinical advice

- Access to Europe's largest dental library and over 500 e-books

- BDA student e-newsletter

- Expert advice

- Access to emotional support with our 24/7 'Health Assured' telephone service and free face-to-face counselling

- Student advisory service - available online and by phone

- Dedicated student resources including our Getting your first job guide and Career guide

- Helpful dental school lectures on careers and interview skills

- Access to our DFT interview skills workshop - for fifth years

- f30 discount on BDSA Conference and BDSA Sports Day tickets

- £100 discount on Orascoptic loupes

- Financial hardship grants/loans from the BDA Benevolent Fund.

https://doi.org/10.1038/s41406-020-0169-z 